\title{
Numerical simulations for allocations of internal forces on double-layer linings of shield tunnel
}

\author{
SHANGGUAN Zichang ${ }^{1, a^{*}}$, LI Shouju ${ }^{2, b}$ and LI Hao ${ }^{3, c}$ \\ ${ }^{1}$ Institute of Marine and Civil Engineering, Dalian Ocean University, China \\ ${ }^{2,3}$ State Key Laboratory of Structural Analysis for Industrial Equipment, Dalian University of \\ Technology, China \\ a shangguan@dlou.edu.cn, ${ }^{\mathrm{b}}$ lishouju@dlut.edu.cn, ${ }^{\mathrm{c}} 13478475424 @ q q . c o m$
}

\begin{abstract}
Keywords: Double-layer linings of shield tunnel; Second lining concrete; Bending moment allocation ratio; Finite element method; Internal forces

Abstract. Finite element model is performed to simulate the interactions between soils and concrete segments. A practical engineering example for double-layer linings of shield tunnel is numerically simulated with FEM in order to compute bending moment allocation ratio between bending moment on the initial lining segments and bending moment on the second concrete linings. Under the commonly designing thicknesses for double-layer linings of shield tunnel, with segment thickness $h_{1}=0.5 \mathrm{~m}$ and second lining thickness $h_{2}=0.2 \mathrm{~m}$, the bending moment on initial lining segment burdens $97 \%$ of total moment on double-layer linings. So, the structural feature of the second lining concrete can be ignored.
\end{abstract}

\section{Introduction}

Shield-driven tunnels are widely adopted in the development of underground spaces for transportation and utility networks in soft soils. Numerical modeling has now become an important element in the design of underground excavations in soils and rocks. Numerical analysis can provide realistic representation of the field conditions taking into account key elements of the excavation such as the geomechanical characteristics of the ground and the in situ stress condition. The design of any tunnel structure has to fulfill some basic requirements concerning structure stability, durability, water tightness and reliability, low costs and low-risk profile. To achieve these goals it is necessary that engineers have an opportunity to predict unwanted effects. Although it is difficult to translate the reality of tunnel lining behaviour into a mechanical mathematical engineering model, it is absolutely essential that this be done. The guideline for the design of shield tunnel lining was proposed by International Tunnelling Association in 2000 [1], which suggested basic approaches for computing internal forces on concrete segments. Molins performed experimental and analytical study of the structural response of segmental tunnel linings, the investigation results posed meaningful for computing internal forces on concrete segments[2]. Arnau investigated three dimensional structural response of segmental tunnel linings, and transversal and longitudinal mending characteristics segmental tunnel linings were analyzed [3]. Do performed 2D numerical investigation of segmental tunnel lining behavior[4], Chen numerically simulated crack problems in segments of shield tunnel using finite element method[5], Yuan Tunnel carried out structure analysis using the multi-scale modeling method[6], Mashimo proposed a procedure to evaluate the load on shield tunnel lining in gravel [7], Kim presented a prediction method of tunnel lining loads using correction factors[8], Moller investigated the ground loss ratio problems with considering tunnel installation process[9]. Li analyzed influences of ground loss ratios on internal force characteristics on segments of tunnel linings. Based on measurement data of ground surface settlements in field, the ground loss ratio was determined. The predicted surface settlements with FEM were in good agreement with field observations [10].The aim of the paper is to numerically simulate allocations of internal forces on double-layer linings of shield tunnel and analyze the he structural feature of the second lining concrete. 


\section{Numerical Computing Models for Allocations of Internal Forces}

Taking an underground railway tunnel under Yangzi river in Wuhan as an engineering example, the water depth is $30 \mathrm{~m}$. As shown in Fig. 1, the thickness of upper soil layer is $20 \mathrm{~m}$, the thickness of middle soil layer is $12 \mathrm{~m}$, and the thickness of lower soil is $20 \mathrm{~m}$. The outer diameter and thickness of initial lining segments are $11.4 \mathrm{~m}$ and $h_{1}=0.5 \mathrm{~m}$, respectively. The thickness of the second lining concrete is $h_{2}=0.2 \mathrm{~m}$. Basic mechanical parameters of concrete materials and soils are listed in Table 1 .

Table 1 Basic mechanical parameters of concrete materials and soils

\begin{tabular}{llll}
\hline \multicolumn{1}{c}{ Materials } & $\rho\left[\mathrm{kg} / \mathrm{m}^{3}\right]$ & & $\mu[\mathrm{Mpa}]$ \\
\hline Soil A (upper soil) & 1800 & 18.0 & 0.40 \\
Soil B (middle soil) & 1900 & 20.0 & 0.42 \\
Soil C (lower soil) & 2200 & 200.0 & 0.25 \\
Concrete segment & 2400 & 34500 & 0.167 \\
Second lining & 2400 & 30000 & 0.167 \\
\hline
\end{tabular}

$\mathrm{P}$

A

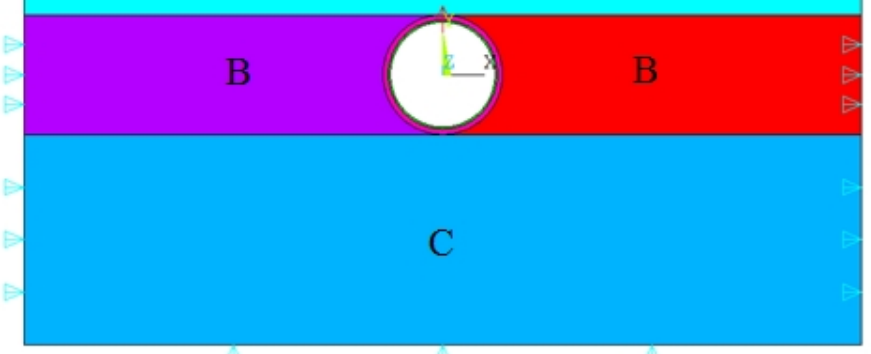

Fig. 1 FEM model of double-layer linings for computing internal forces

As shown in Fig. 1, the water pressure $(\mathrm{P}=300 \mathrm{kPa})$ is loaded on the upper boundary of FEM model. The right and left boundaries of FEM model are fixed in the horizontal direction. The lower boundary of FEM model is fixed in the vertical direction. The beam element, named as Beam 3 in ANSYS software, was used to simulate initial lining segments. The plane element was used to simulated soil layers and second lining concrete. The plane strain is assumed in numerical simulation.

\section{Numerical Simulations for Allocations of Internal Forces}

The numerical simulations of interactions between soil layers and concrete segments are performed in ANSYS software. The internal force distributions on initial lining segments and second lining concretes are computed. The ratio $\left(\eta_{1}\right)$ between bending moment on the initial lining segment and total moment on double-layer linings is defined as

$$
\eta_{1}=\frac{M_{1}}{M_{1}+M_{2}} \%
$$

Where $M_{1}$ is maximum value on the initial lining segment; $M_{2}$ is maximum value on the second lining concrete. The ratio $\left(\eta_{2}\right)$ between bending moment on the second lining concrete and total moment on double-layer linings is defined as

$$
\eta_{2}=\frac{M_{2}}{M_{1}+M_{2}} \%
$$




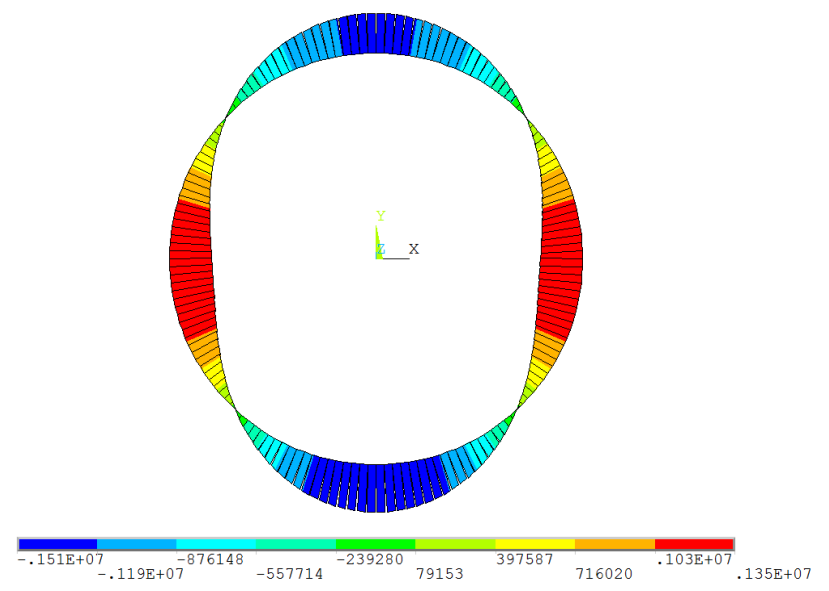

Fig. 2 Bending moment distribution on initial lining concrete segment (unit: $\mathrm{N} \cdot \mathrm{m} / \mathrm{m}$ )

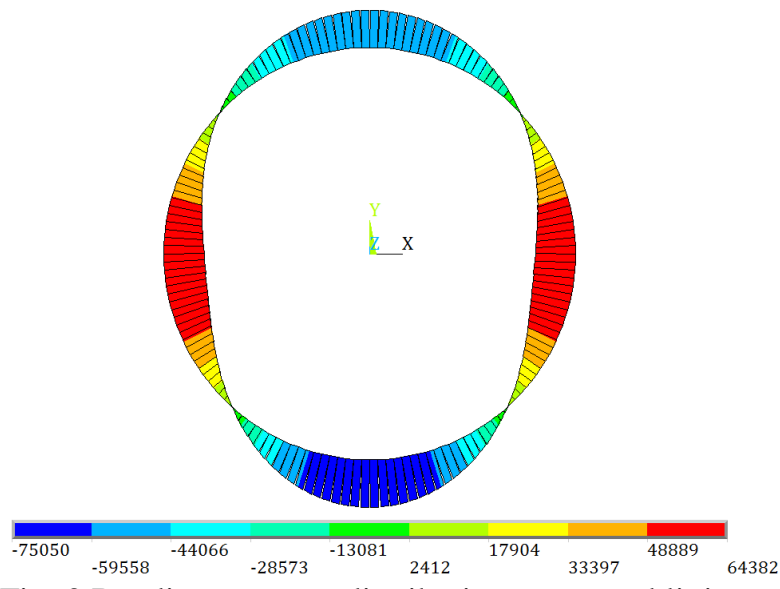

Fig. 3 Bending moment distribution on second lining concrete (unit: $\mathrm{N} \cdot \mathrm{m} / \mathrm{m}$ )

From Fig. 2 and Fig. 3, it can be observed that the maximum bending moments on initial lining concrete segment and second lining concrete are $M_{1 \max }=1510 \mathrm{kN} \cdot \mathrm{m} / \mathrm{m}$ and $M_{2 \max }=75 \mathrm{kN} \cdot \mathrm{m} / \mathrm{m}$, respectively. The bending moment ratio $(\xi)$ between bending moments on second lining concrete and on the initial lining segment is defined as

$$
\begin{aligned}
\xi & =\frac{M_{2}}{M_{1}} \% \\
& =\frac{I_{2}}{I_{1}} \% \\
& =\left(\frac{h_{2}}{h_{1}}\right)^{3} \%
\end{aligned}
$$

Where $I_{1}$ and $I_{2}$ are inertia moments of initial lining segment and second lining concrete, respectively. The ratio $(\xi)$ is $5 \%$ while the thickness of initial lining segment is $h_{1}=0.5 \mathrm{~m}$ and the thickness of second lining concrete is $h_{2}=0.2 \mathrm{~m}$. Axial force distributions on initial lining concrete segment and on second lining concrete are illustrated in Fig. 4 and 5. Shear force distribution on initial lining concrete segment and on second lining concrete are illustrated in Fig. 6 and 7 .

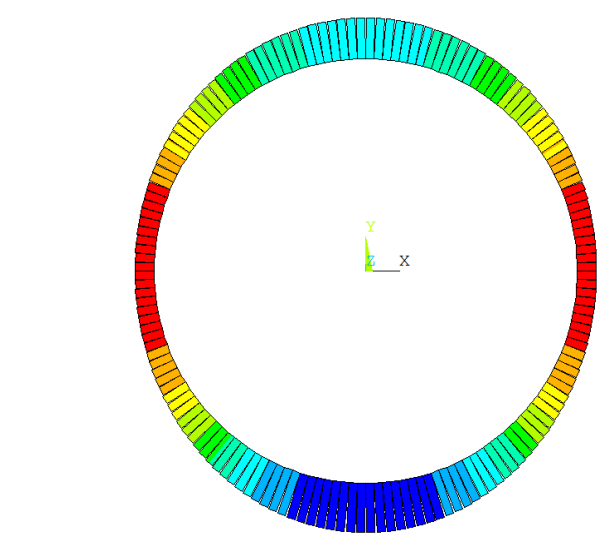

Fig. 4 Axial force distribution on initial lining concrete segment (unit: N/m)
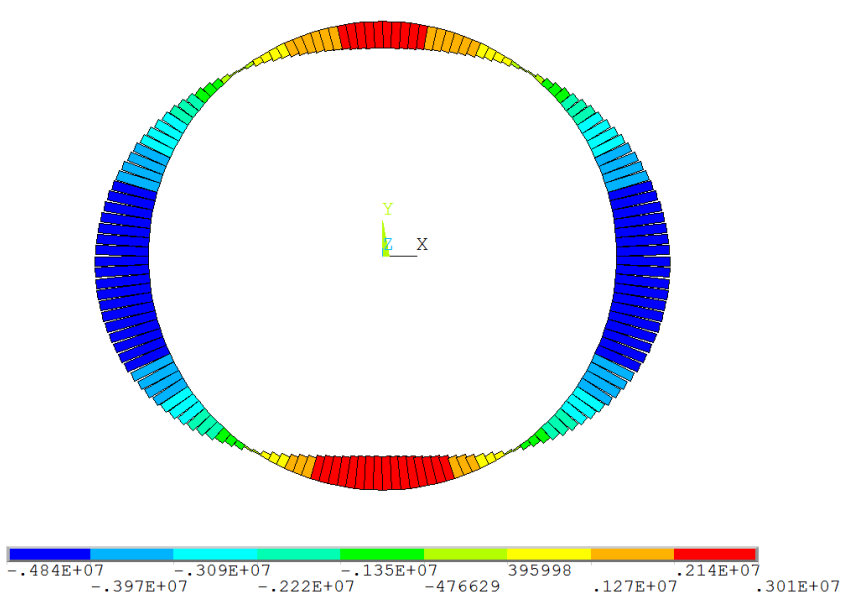

Fig. 5 Axial force distribution on second lining concrete (unit: N/m) 

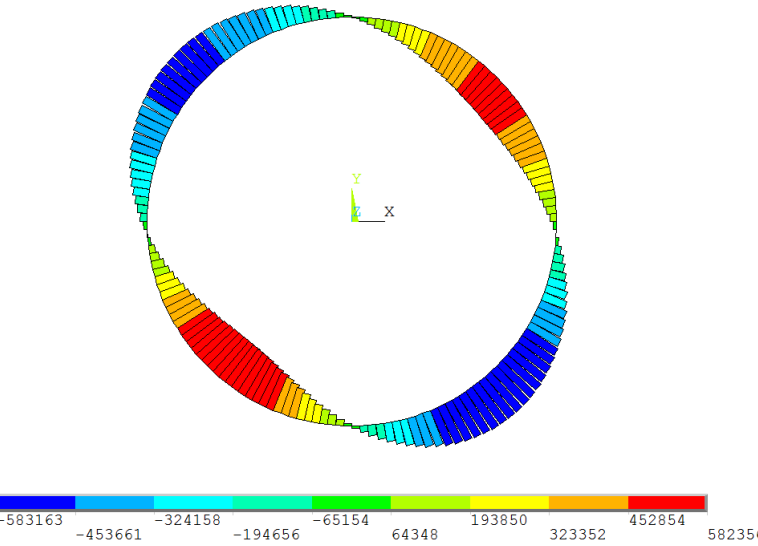

Fig. 6 Shear force distribution on initial lining concrete segment (unit: N/m)

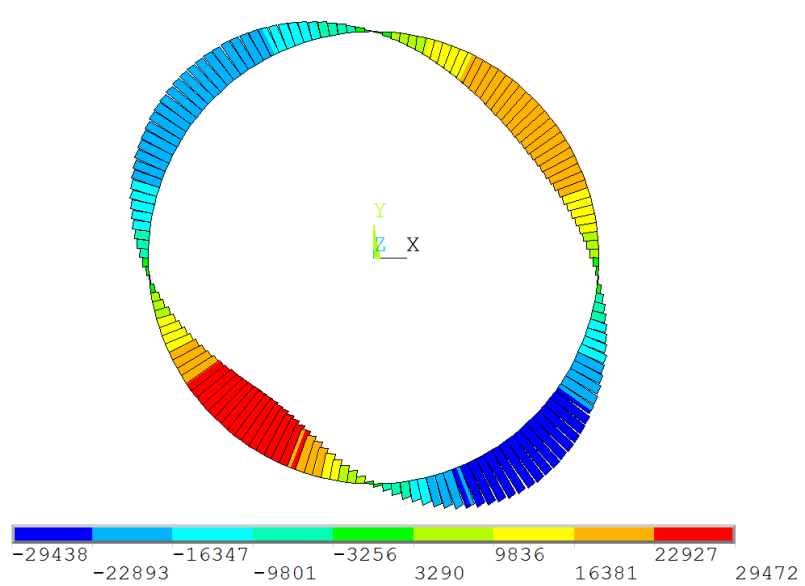

Fig. 7 Shear force distribution on second lining concrete (unit: N/m)

\section{Conclusions}

1) The ratio $(\xi)$ between bending moment on second lining concrete and bending moment on the initial lining segment is proportional to the ratio between the inertia moment of second lining concrete and the inertia moment of initial lining segment.

2) Under the commonly designing thicknesses for double-layer linings of shield tunnel, with segment thickness $h_{1}=0.5 \mathrm{~m}$ and second lining thickness $h_{2}=0.2 \mathrm{~m}$, the bending moment on the second lining concrete beam only burdens $3 \%$ of total moment on double-layer linings. So, the structural feature of the second lining concrete can be ignored.

3) The further investigation should focus on the structural feature of the second lining concrete in case of leaking status of initial lining segment.

\section{Acknowledgement}

The research described in this paper was financially supported by the National Key Basic Research and Development Program of China (Grant No. 2015CB057804) and Opening Foundation of State Key Laboratory of Structural Analysis for Industrial Equipment (Grant No. S14206).

\section{References}

[1] Working Group No. 2. International Tunnelling Association. Guidelines for the Design of Shield Tunnel Lining, Tunnelling and Underground Space Technology 15(3)( 2000) 303-332.

[2] Climent M. , Oriol A. , Experimental and analytical study of the structural response of segmental tunnel linings based on an in situ loading test. Part 1: Test configuration and execution. Tunnelling and Underground Space Technology, 26 (6)(2011) 764-777.

[3] Oriol A. , Climent M. , Three dimensional structural response of segmental tunnel linings. Engineering Structures 44(2012) 210-221.

[4] Ngoc-Anh D. , Daniel D. P. O., Irini D. M. , 2D numerical investigation of segmental tunnel lining behavior. Tunnelling and Underground Space Technology, 37(2013) 115-127.

[5] Chen, J.S., Mo, H.H., Numerical study on crack problems in segments of shield tunnel using finite element method. Tunneling and Underground Space Technology, 24 (2009) 91-102.

[6] Yuan, C., Wang, P.Y., Jin, X.L., Tunnel structure analysis using the multi-scale modeling method. Tunneling and Underground Space Technology 28(2012)124-134. 
[7] Mashimo, H., Ishimura, T. , Evaluation of the load on shield tunnel lining in gravel. Tunneling and Underground Space Technology 18(2003) 233-241.

[8] Kim, H.J., Eisenstein, Z. , Prediction of tunnel lining loads using correction factors. Engineering Geology 85(2006) 302-312.

[9] Moller, S.C., Vermeer, P.A., On numerical simulation of tunnel installation. Tunneling and Underground Space Technology 23(2008) 461- 475.

[10] Li S., Shangguan Z. , Influences of Ground Loss Ratios on Internal Force Characteristics on Segments of Tunnel Linings. Electronic Journal of Geotechnical Engineering 20(10)( 2015) 4223-4232. 